\title{
Characterization of raffia palm fiber for use in polymer composites
}

\author{
Opeoluwa Fadele ${ }^{1}$ ○ Ikechukwuka N. A. Oguocha ${ }^{1} \cdot$ Akindele Odeshi $^{1} \cdot$ Majid Soleimani $^{2} \cdot$ Chithra Karunakaran $^{3}$
}

Received: 20 March 2018 / Accepted: 22 June 2018 / Published online: 25 July 2018

(C) The Japan Wood Research Society 2018

\begin{abstract}
Raffia palm fibers are potential reinforcement materials for making cost-effective polymer-based composite. This paper presents the results obtained from a study of physical, chemical, thermal and mechanical properties of raffia palm fibers (RPFs) derived from the raffia palm tree (Raphia farinifera). The as-received RPFs had their remnant binders manually removed and was subsequently cleaned in a $2 \%$ detergent solution before drying in an air oven at $70{ }^{\circ} \mathrm{C}$ for $24 \mathrm{~h}$. Evaluation of the properties of the dried samples was carried out using a combination of characterization techniques including chemical composition determination, density measurement, moisture adsorption and water absorption measurements, tensile testing, scanning electron microscopy (SEM), differential scanning calorimetry (DSC), Raman spectroscopy, X-ray diffractometry, and Fourier transform infrared spectromicroscopy. The main constituents of RPFs were found to be cellulose, hemicellulose and lignin. The average diameter and average density were $1.53 \pm 0.29 \mathrm{~mm}$ and $1.50 \pm 0.01 \mathrm{~g} / \mathrm{cm}^{3}$, respectively. The average breaking strength of the fibers ranged from $152 \pm 22$ to $270 \pm 39 \mathrm{MPa}$; it did not vary significantly with fiber length and cross-head speed during tensile testing. The results of scanning electron microscopic investigation of the fibers showed that they comprise several elemental fibers which are tightly packed together with each having its own lumen. Synchrotron-based Fourier-transform infrared spectromicroscopy of a cross-section of the fiber showed that lignin is concentrated mostly on the outside while cellulose and pectin are concentrated in the mid-section. A two-stage water sorption behavior was observed for the fibers.
\end{abstract}

Keywords Raffia palm fiber · Mechanical properties $\cdot$ Thermal properties $\cdot$ Synchrotron $\cdot$ Infrared spectroscopy

\section{Introduction}

The mechanical properties of polymers are inadequate for many structural purposes, particularly their strength and stiffness which are lower than those of ceramics and metals [1]. This difficulty is commonly overcome by reinforcing them with stronger and stiffer components such as synthetic and natural fibers (NFs). Reinforcement leads to improved mechanical properties and widens structural applications of

Opeoluwa Fadele

ope.fadele@usask.ca

1 Department of Mechanical Engineering, College of Engineering, University of Saskatchewan, 57 Campus Drive, Saskatoon, SK S7N 5A9, Canada

2 Department of Biological Engineering, College of Engineering, University of Saskatchewan, 57 Campus Drive, Saskatoon, SK S7N 5A9, Canada

3 Canadian Light Source Inc., 44 Innovation Boulevard, Saskatoon, SK S7N 2V3, Canada polymers [2]. However, it is equally recognized that composites made from synthetic reinforcements pose severe environmental pollution problems [3]. Hence, the increasing interest is in the use of NFs for making polymer matrix composites (PMCs). Natural fibers, which are sourced mostly from plants, are inexpensive, renewable and biodegradable. Some NFs have mechanical properties comparable to those of synthetic fibers [4]. Although several studies reported on the use of natural fibers such as flax [5, 6], sisal [7-9], abaca [10-12], banana [1, 13, 14], coir [15, 16], pineapple [17] and ramie [18] to manufacture PMCs, very little attention has been given to the potential use of raffia palm fibers in polymer composites [3]. They can also be used to reinforce concretes and clay bricks or make geotextiles [3].

Like sisal, banana, henequen and abaca fibers, raffia palm fibers are plant leave fibers which are extracted from the leaflets of a raffia palm tree-Raphia farinifera. Raffia palm tree are grown in the tropical equator region areas of Africa, Madagascar and South America [19, 20]. There are about 28 different species of raffia fibers that grow in the tropics 
[21]. The entire raffia palm tree is used for various purposes. Edible and cosmetic oils are extracted from its nuts; a white tasty liquid, known as palm wine, is collected from its sap; and the fibers extracted from the leaves are used for making textiles (e.g. carpets and mats), fabrics, dresses, ropes, objects of arts, and ligatures for grafting [3, 19]. To date, there are very few studies on the microstructure, chemical, physical, thermal, and mechanical properties of raffia palm fibers $[3,19,22]$. This study fills the gap in the current knowledge of these fibers by providing additional property information which will help in the assessment of their potential use as reinforcements in polymeric materials.

\section{Materials and methods}

\section{Material}

The raffia palm fibers (RPFs) used in this study were obtained from southern Nigeria. Remnant binders sticking to the fibers were manually removed with $3 \mathrm{M}$ ProGrade Precision $3.7 \times 9$ Sanding Sheets 220 grit papers. The resulting fibers were soaked in $2 \%$ formulated detergent solution for $10 \mathrm{~min}$ and cleaned to remove oily substances and other impurities on the fiber surface. After cleaning, the fibers were dried in an air oven at $70{ }^{\circ} \mathrm{C}$ for $24 \mathrm{~h}$ and subsequently cooled to room temperature before further testing. The diameter of the cleaned fibers was determined using a micrometer screw gauge. 28 fibers were chosen at random and their diameters measured at ten locations along each fiber to account for non-uniformity in diameter along the fiber length. The average fiber diameter obtained is $1.53 \pm 0.3 \mathrm{~mm}$. Fibers used for chemical composition, density determination, thermal analysis, X-ray diffraction and spectroscopic analyses were ground and sieved using a $1 \mathrm{~mm}$ screen. Figure 1 shows photographs of the as-cleaned and ground fibers. The particle density of the fibers was measured at room temperature using a gas pycnometer (Quantachrome Instruments, USA). The average density obtained for the ground fibers is $1.50 \pm 0.01 \mathrm{~g} / \mathrm{cm}^{3}$, which is very close to the value reported by Sandy and Bacon [19].

\section{Chemical composition}

This test was performed to determine the chemical composition (cellulose, hemicellulose, and lignin contents) of RPFs. It was carried out in an Ankom 200 Fiber Analyzer ${ }^{\mathrm{TM}}$ (ANKOM Technology, USA) in accordance with the detergent fiber analysis method developed by Peter Van Soest [23, 24]. The standard acid detergent fiber (ADF), neutral detergent fiber (NDF) and acid detergent lignin (ADL) analyses were conducted using Ankom 200 Method 5 [25], Method 6 [26] and Method 8 [27] procedures, respectively. $0.5 \mathrm{~g}$ of cleaned and dried fibers which were ground to pass $1 \mathrm{~mm}$ screen was used for each analysis. Each test was repeated three times. For ADF measurement, $0.5 \mathrm{~g}$ of the sample was placed in an Ankom bag and was extracted in an ADF solution consisting of cetyl trimethylammonium bromide $(\mathrm{CTAB})$ and $1.00 \mathrm{~N}$ sulfuric acid. Extraction was conducted at $100 \pm 0.5{ }^{\circ} \mathrm{C}$ for $1 \mathrm{~h}$ and, at the end, the ratio of the dried solid phase obtained through filtration to the original mass of the material was reported as ADF. The NDF value was determined by digestion of the sample at $100 \pm 0.5^{\circ} \mathrm{C}$ for $1 \mathrm{~h}$ in a solution consisting of sodium dodecyl sulfate, ethylene diamine tetra acetic disodium salt, sodium borate, sodium phosphate dibasic, tri-ethylene glycol, alpha-amylase, and sodium sulfite. The ratio of the dried solid fraction obtained from filtration of the slurry to the original mass of the sample was reported as NDF percentage. The ADL test was conducted by digestion of the sample in a $72 \%$ sulfuric acid solution for $3 \mathrm{~h}$ and mixing of the sample in the solution at 30-min intervals, followed by rinsing with enough water until neutralization, and finally with acetone wash and drying of the solid residue. The ratio of the dried solid residue to the original mass of the sample was reported as ADL percentage. The cellulose content was calculated from the difference between the ADF and ADL values; the hemicellulose content was based on the difference between the NDF and ADF values, while ADL value provided the lignin content. Three different measurements were taken, and the data reported in this paper are the average values for these three runs (dry-matter basis).
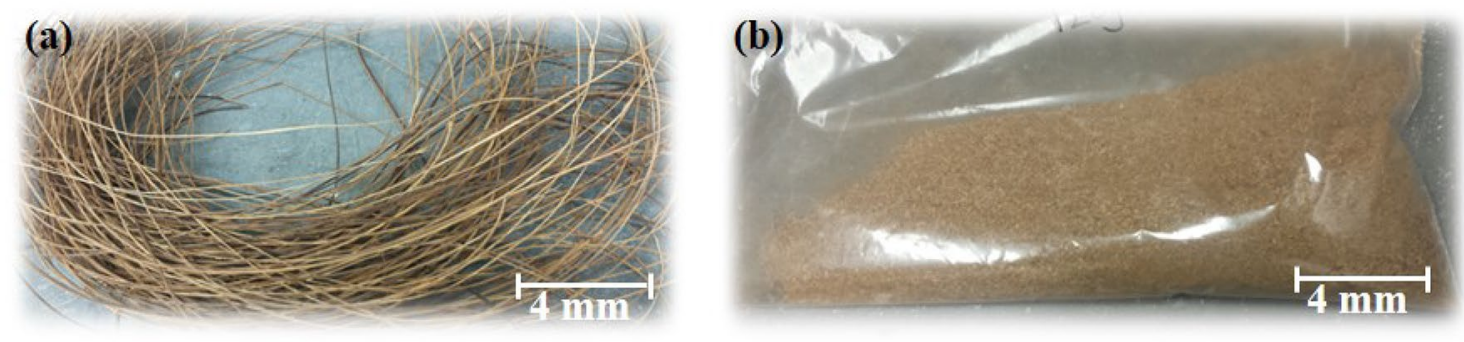

Fig. 1 Photographs of $\mathbf{a}$ as-cleaned and $\mathbf{b}$ ground raffia palm fiber 


\section{Microstructure}

RPFs were cold mounted for polishing the outside using acrylic resin to produce a smooth fiber surface for imaging. The cold-mounted samples were pre-ground using 320 $(46 \mu \mathrm{m}), 500(30 \mu \mathrm{m})$ and $1200(15 \mu \mathrm{m}) \mathrm{SiC}$ grit emery papers. This was followed by fine grinding using 2000 $(10 \mu \mathrm{m})$ and $4000(5 \mu \mathrm{m}) \mathrm{SiC}$ grit emery papers. Final polishing was done using $1 \mu \mathrm{m}$ MD-Nap cloth with $1 \mu \mathrm{m}$ MDNap suspension. The samples were subsequently gold-coated using an Edward S150B sputter coater (BOC Edwards, UK) before imaging. The microstructure of the polished samples were examined using a Hitachi FE-SEM SU8010 (Hitachi High-Technologies Corporation, Japan) scanning electron microscope. The SEM images were acquired using an accelerating voltage of $3 \mathrm{kV}$.

\section{Tensile test}

Tensile test was performed to determine mechanical properties of the fiber. It was conducted according to ASTM D3822-14 standard [28] using a $5 \mathrm{kN}$ capacity Model 3366 Instron ${ }^{\circledR}$ Universal testing machine (Instron ${ }^{\circledR}$, USA) at a crosshead speed of $1 \mathrm{~mm} / \mathrm{min}$. The test was conducted at room temperature and at a relative humidity of $35 \%$. The diameters and cross-sectional area of each fiber used in the test were measured and recorded. The fibers were mounted individually into the grips of the tensile testing machine with the help of tissue papers. A cellophane tape was used to fasten the tissue papers to the fibers to prevent slippage and fracture of the fiber at the points of grip. The fiber lengths were measured from one end of the tensile grip to the other as shown in Fig. 2. Ten different fiber lengths (45, 50, 55, $60,65,70,75,95,120$ and $145 \mathrm{~mm}$ ) were used to study the effect of fiber length on the percent elongation to fracture and tensile strength of RPF. For each fiber length test, five fibers were tested at each length with a gauge length of $25 \mathrm{~mm}$, and the reported data are averages of the five measurements. In addition, the effect of crosshead speed, used during tensile testing, on mechanical properties of the fibers was investigated. Four crosshead speeds $(0.5,1.0,1.5$ and $2.0 \mathrm{~mm} / \mathrm{min}$ ) were used and the fiber length was fixed

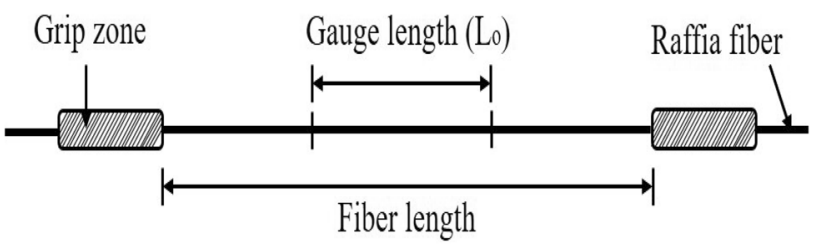

Fig. 2 A schematic drawing of a raffia palm fiber prepared for tensile test at $50 \mathrm{~mm}$. For each test speed, ten fibers were tested and the reported data are averages of the tens measurements.

The obtained tensile test data were analyzed by one-way analysis of variance (ANOVA) to determine if the breaking strength and ductility of the fibers were significantly influenced by fiber length or strain rate. The SigmaPlot for Windows Version 13.0 software (Systat Software Inc., USA) was used in the ANOVA test.

\section{Moisture adsorption measurement}

This test was performed to determine the moisture adsorption capability of dry raffia fibers on exposure to a humid environment. Five samples, each weighing $0.50 \mathrm{~g}$, were dried in an air oven at $70{ }^{\circ} \mathrm{C}$ for over $60 \mathrm{~h}$ to ensure full drying before cooling to room temperature and subsequently placed in a Model 1200 Thunder Scientific Corporation humidity generator (Thunder Scientific Corporation, USA) which was maintained at $23{ }^{\circ} \mathrm{C}$ and $50 \% \mathrm{RH}$, with $0.5 \%$ $\mathrm{RH}$ uncertainty. To study the effect of temperature on the moisture adsorbed, the humidity generator was maintained at $50{ }^{\circ} \mathrm{C}$ and $50 \%$ RH. Sample weight readings were taken at different time intervals between 3 and $58 \mathrm{~h}$. The moisture content (MC) of the fibers (in wt\%) was calculated using Eq. (1).

$\mathrm{MC}_{t}(\mathrm{wt} \%)=\frac{W_{t}-W_{0}}{W_{0}} \times 100$,

where $W_{0}$ and $W_{t}$ denote the dry weight of raffia fibers and weight of the fibers after a specific time $t$, respectively.

\section{Water absorption}

The purpose of this test was to determine the water absorption capability of dry raffia fibers. Five samples, each weighing $0.50 \mathrm{~g}$, were used in this experiment. The fibers were dried for up to $60 \mathrm{~h}$ in an oven maintained at $70{ }^{\circ} \mathrm{C}$, cooled to room temperature and weighed. The fibers were then immersed in a water bath containing distilled water maintained at room temperature. They were removed from the water bath at different times, the surface cleaned to remove any water and weighed within $30 \mathrm{~s}$ to ensure no evaporation effect. The weight was recorded as a function of time until the saturation limit was reached. The water content (WC) of the fibers (in wt \%) was computed using Eq. (2).

$\mathrm{WC}_{t}(\mathrm{wt} \%)=\frac{W_{t}-W_{0}}{W_{0}} \times 100$.

\section{X-ray diffraction (XRD)}

X-ray diffraction measurement was carried out using a PANalytical Empyrean X-ray diffractometer (Malvern 
PANalytical, UK) with a Co target, rotating stage and goniometer in $2 \theta$ configuration. The wavelength of Co radiation is $0.179 \mathrm{~nm}$. The intensities were measured for $2 \theta$ ranging from $5^{\circ}$ to $110^{\circ}$ with a step size of $0.0167^{\circ}$ and a scan speed of $0.015^{\circ} / \mathrm{s}$. The radiation used was full spectrum Co $\left(K_{\alpha 1}\right.$, $K_{\alpha 2}$ ) with the $K_{\beta}$ filtered out with a diffracted side Fe filter. The results were analyzed using PANalytical X' Pert HighScore Version 4.6 software (Malvern PANalytical, UK). The empirical equation proposed by Segal et al. [29] was used to estimate the degree of crystallinity (crystallinity index, CI) of the fibers:

$\mathrm{CI}(\%)=\frac{I_{002}-I_{\mathrm{am}}}{I_{002}} \times 100$,

where $I_{002}$ corresponds to the (002) lattice reflection peak (the maximum intensity) at an angle of $2 \theta$ (around $22^{\circ}$ ). $I_{\mathrm{am}}$ corresponds to the height of the minimum peak position between (002) and the (110) peaks and is attributed to the amorphous fraction (minimum intensity) located at about $18^{\circ}$. The assignment of diffraction peaks was carried out in accordance with the works of Sathitsuksanoh et al. [30] and Du et al. [31].

\section{Synchrotron-based Fourier-transform infrared spectromicroscopy (FTIRS)}

This test was performed to determine the spatial distribution of the different chemical components of RPF. The samples for the FTIRS were prepared by cross-sectioning the fibers to $6 \mu \mathrm{m}$ thin samples using a Leica CM1950 cryostat (Leica Biosystems Inc., USA) and mounted on $\mathrm{CaF}_{2}$ windows $\left(\mathrm{CaF}_{2}\right.$ Polished Disc-25 $\mathrm{mm}$ diameter and $2 \mathrm{~mm}$ thick). Images were collected using the Bruker Vertex 70v Interferometer Hyperion 3000 IR Microscope (Bruker Optics Inc., USA). The synchrotron-based FTIRS technique was used with the microscope, equipped with a focal plane array (FPA) detector which is located at the mid-infrared beamline (01B1-1), Canadian Light Source, Saskatoon. The FPA detector enabled the spectra from various parts of the sample to be collected simultaneously. A tile of $170 \times 170 \mu \mathrm{m}$ step sizes having 4,096 data points was mapped in both the $x$ and $y$ directions of the fiber. A complete IR spectrum was collected at each spot $\left(400-4000 \mathrm{~cm}^{-1}\right)$ with a resolution of $4 \mathrm{~cm}^{-1}$ in the transmission mode. The data collected were analyzed using the OPUS software Version 7.0 (Bruker, USA).

\section{FTIR and Raman spectroscopy}

Fourier-transform infrared (FTIR) and Raman spectroscopic techniques were used to determine chemical structure associated with RPFs. These techniques provide complementary information on the chemical structure associated with RPF $[32,33]$. The study was carried out using a Renishaw Raman inVia Reflex Microscope (Renishaw Inc, West Dundee, IL, USA). In the macroscopic mode, a sample area of $100 \mu \mathrm{m}$ diameter was examined using a low laser power of approximately $50 \mathrm{~mW}$ to minimize sample degradation. Raman spectra were recorded over the range of $3500-200 \mathrm{~cm}^{-1}$ at a scan rate of $32 \mathrm{~cm}^{-1}$. The microscope has a Smith's IllumminantIR II ${ }^{\mathrm{TM}}$ accessory that allows FTIRS data to be acquired using an all-reflective objective (ARO) and a diamond attenuated total reflection (ATR) objective. The mercuric cadmium telluride (MCT) detector on the IllumminantIR II ${ }^{\mathrm{TM}}$ spectrometer was cooled with liquid nitrogen. The spectra were obtained with an accumulation of 512 scans with a resolution of $4 \mathrm{~cm}^{-1}$.

\section{Differential scanning calorimetry (DSC)}

The thermal stability of RPFs was determined using a model 2910 V4.4E TA Instruments modulated differential scanning calorimeter (MDSC) (TA Instruments, USA). Each scan was performed under argon gas in an open aluminum pan from room temperature to $390{ }^{\circ} \mathrm{C}$ at a heating rate of $5^{\circ} \mathrm{C} /$ $\min$. Two sets of fibers were analyzed. Ground fibers conditioned at the laboratory conditions of $50 \%$ relative humidity and $23{ }^{\circ} \mathrm{C}$ for a week are denoted as-received RPFs, while ground fibers kept in a desiccator for a week are designated as dried RPFs. Approximately $10 \mathrm{mg}$ each of as-received and dried fibers were used and the DSC measurement was repeated twice to ensure reproducibility.

\section{Results and discussion}

\section{Chemical composition of raffia palm fiber}

The chemical composition (dry matter basis) of the RPF obtained in this study are compared with those of some leaf fibers in Table 1. RPF comprises cellulose (53 wt \%), hemicellulose (13 wt \%) and lignin (24 wt\%). The remaining $10 \mathrm{wt} \%$ is attributed to other components (e.g. pectin, wax, and ash) which could not be quantified using the Ankom 200 Fiber Analyzer ${ }^{\mathrm{TM}}$. In comparison to other leaf fibers listed in Table 1, the raffia palm fiber investigated in the present work has the lowest cellulose content but has the highest wt $\%$ of lignin. Its hemicellulose content is less than those of abaca, sisal and pineapple but roughly the same as that of banana. Cellulose is the key structural component of natural fibers; the strength and stiffness of NFs depend on cellulose content and the spiral angle of cellulose microfibrils [8]. Therefore, it is expected that the strength of RPF will be lower than the other leaf fibers. On the other hand, since cellulose is hydrophilic in nature, the implication here is that untreated 
Table 1 Chemical composition of RPF and some natural leaf fibers

\begin{tabular}{lllll}
\hline Fiber & $\begin{array}{l}\text { Cellulose } \\
(\text { wt\% })\end{array}$ & $\begin{array}{l}\text { Hemicellulose } \\
(\text { wt\% })\end{array}$ & $\begin{array}{l}\text { Lignin } \\
(\mathrm{wt} \%)\end{array}$ & References \\
\hline Abaca & $56-63$ & $20-25$ & $7-9$ & {$[11]$} \\
Sisal & 65.8 & 12 & 9.9 & {$[9]$} \\
Banana & $60-65$ & $6-19$ & $5-10$ & {$[13]$} \\
Pineapple & $70-82$ & - & $5-12$ & {$[17]$} \\
Raffia palm fiber & $53 \pm 0.9$ & $13 \pm 1.2$ & $24 \pm 2.8$ & Present study \\
\hline
\end{tabular}

raffia palm fiber will be less hydrophilic than the leaf fibers listed in the table. Low hydrophilicity is desirable in natural fibers that will be used as a reinforcement in thermoplastic polymers.

\section{Microstructure}

Figure 3 shows typical SEM micrographs obtained from a transverse section of a RPF. The morphology of the raffia palm fiber is similar to those of other natural fibers. As shown in Fig. 3a, it comprises essentially three distinct regions: a porous inner region consisting of large lumens labeled 1, a more compact middle region labeled 2 and a very thin outer surface (epidermis) labeled 3. Between the outer surface and the inner core, there are two radial pathways labeled 4 which probably serve as conduits for water/ moisture exchange between the core of the fiber and the surrounding medium or environment. The expanded view of the inner region shown in Fig. 3b shows that the fiber consists of many single-walled elementary fibers each with its own lumen. Although the mid-section of the fiber appears more compact at low magnification than the inner region, a
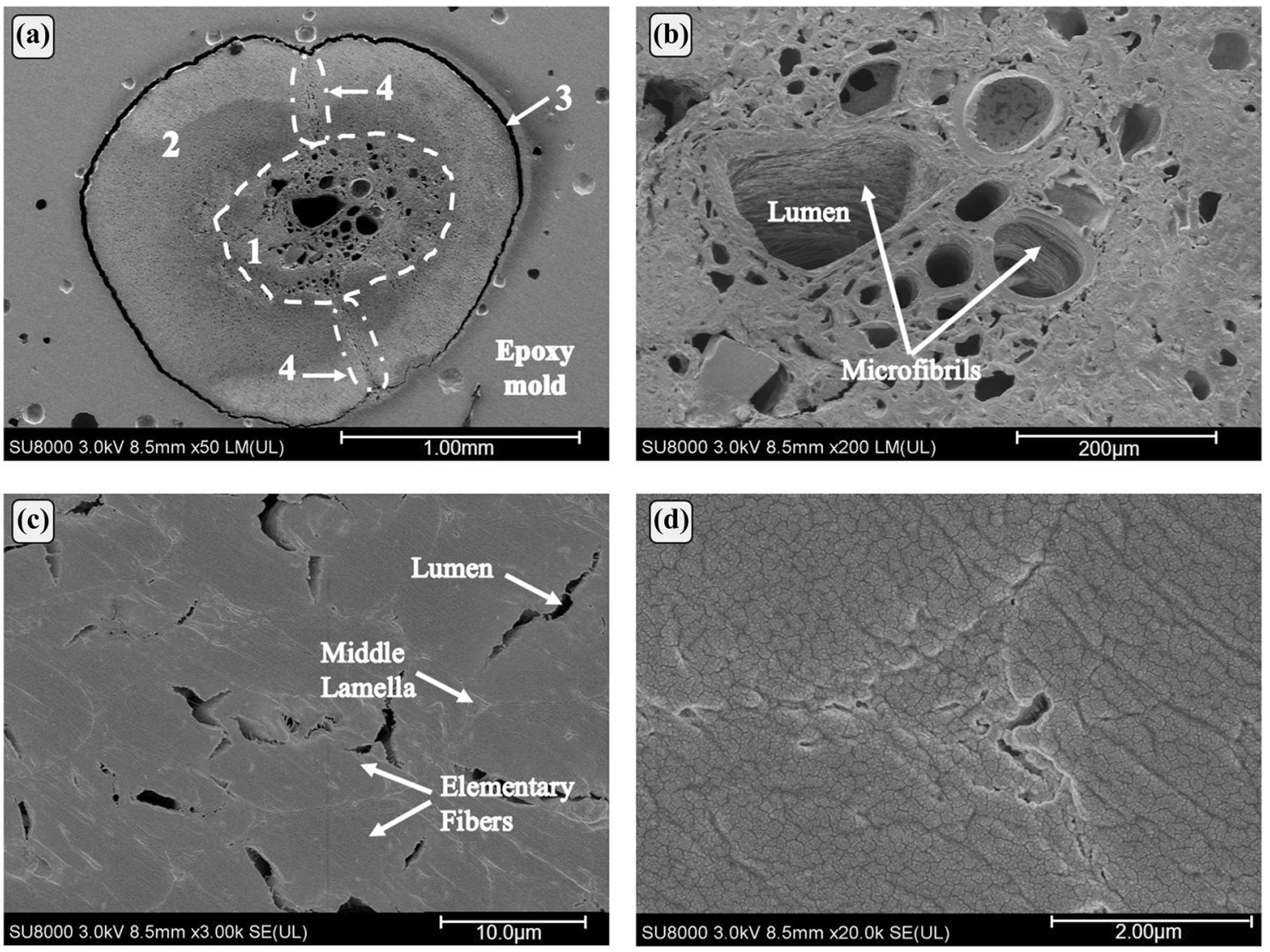

Fig. 3 Typical SEM micrographs showing a the transverse section of a RPF, where label $1=$ inner central region, $2=$ compact middle central region, $\mathbf{c}$ enlarged view of the middle region and $\mathbf{d}$ enlarged view of the middle lamella 
close examination of Fig. 3c shows that it is also made up of numerous elementary fibers each having its own local lumen(s). Such lumen distribution within elementary fibers was reported for coir fibers and found to be discontinuous in the fibers and it is contained within every individual elementary fiber [34]. The middle lamella (Fig. 3d) glues the elementary fibers together is made up of lignin and hemicellulose [35, 36]. It can be seen from Fig. 3b, $\mathrm{c}$ that the size of the lumens in the inner region is larger than that of the ones located in elemental fibers.

Figure 4 shows typical SEM images of the surface of raffia palm fibers. Longitudinal surface cracks/defects are observed on the fiber surfaces. Such cracks were reported to affect the fracture behavior of natural fibers [5, 7, 9, 37]. Chinga et al. [5] reported that defect such as kinks present in flax fibers resulted in a longitudinal splitting of the fiber over a large area. They also observed that the fiber started to fracture where a large defect is located and continued until it encountered the next defect along the fiber length. Silva et al. [7] reported increased failure susceptibility in sisal fibers due to the flaws caused by the collapse of weak fiber walls and delamination between elementary fibers.

\section{Mechanical properties}

A typical tensile stress-strain curve obtained for cleaned and dried RPFs is presented in Fig. 5. The fiber initially deformed inelastically after which it deformed elastically until the maximum stress after which fracture occurred. Similar stress-strain profiles were reported by Cai et al. [10], Silva et al. [7], Mathura and Cree [15] for abaca, sisal and Trinidad coir fibers, respectively. The initial non-linear deformation behavior was attributed to a collapse of the weak primary cell walls and delamination between the elemental fibers in the fiber bundle [7].

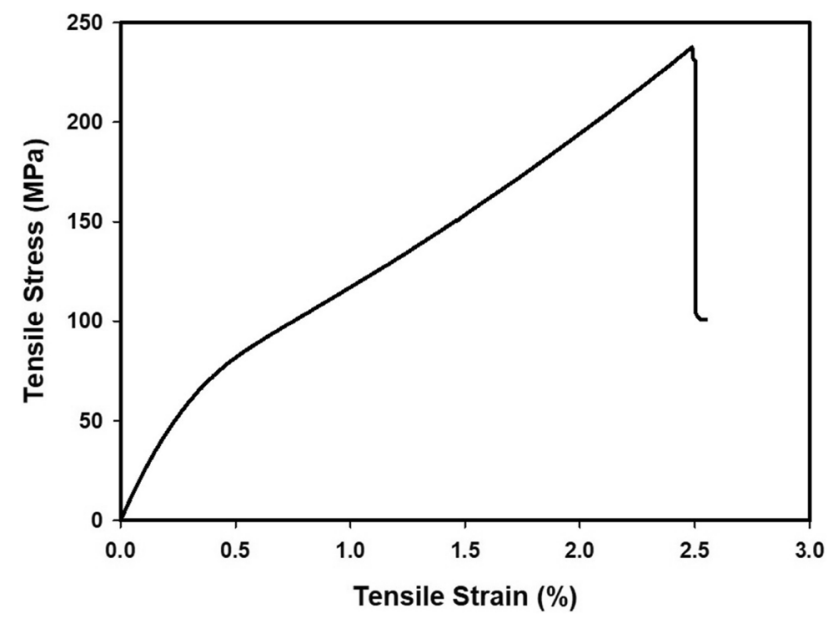

Fig. 5 A typical stress-strain curve obtained for a raffia palm fiber at room temperature

Figure 6 shows the variation of tensile strength and percent elongation to fracture of the RPF with fiber length, while Table 2 compares the tensile strength of RPF to those of the leaf fibers listed in Table 1. There is substantial scatter in the two sets of data due to probably the variability in the measured diameter of the fibers as well as the population, alignment and distribution of internal and surface defects. From Table 2, the average tensile strength of RPF ranged from $152 \pm 22$ to $270 \pm 39 \mathrm{MPa}$, which is better than a tensile strength of $175 \mathrm{MPa}$ reported for coir fiber in [9] and 126.6 MPa reported in [17] for pineapple fiber but less than those of the other leaf fibers. It is also lower than the tensile strength value of $500 \pm 97 \mathrm{MPa}$ reported for Raphia textilis by Elenga et al. [3] and $500 \pm 80 \mathrm{MPa}$ reported for Raphia farinifera by Sandy and Bacon [19]. The differences in the species, harvest time, geographical location and internal
Fig. 4 SEM micrographs showing the surface of untreated RPFs

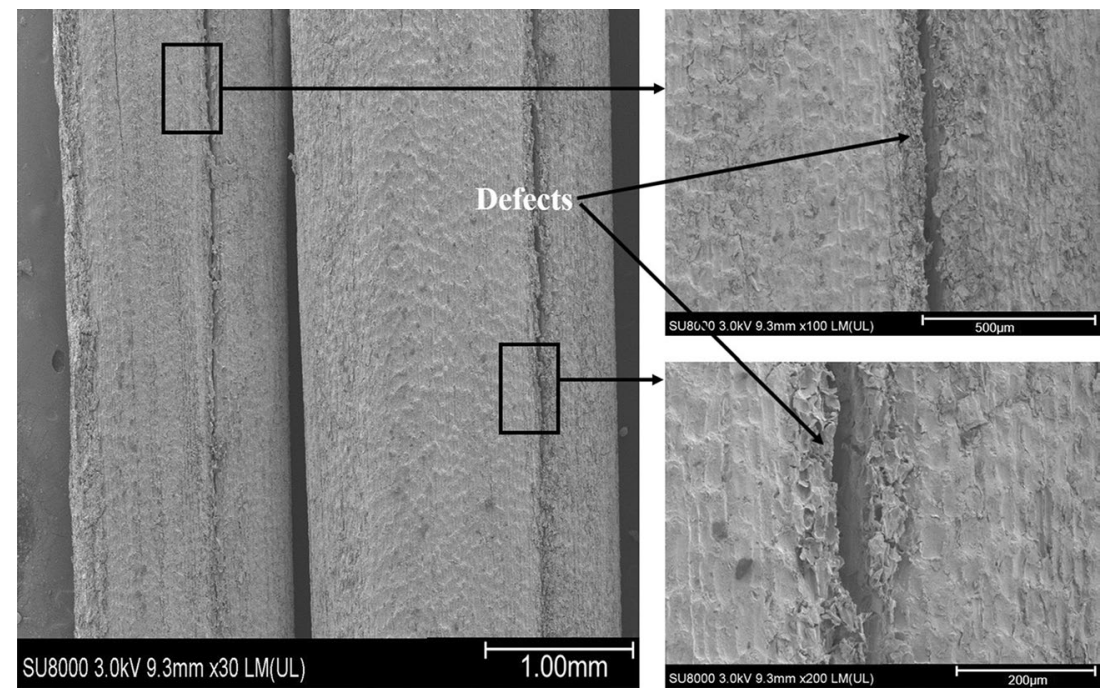



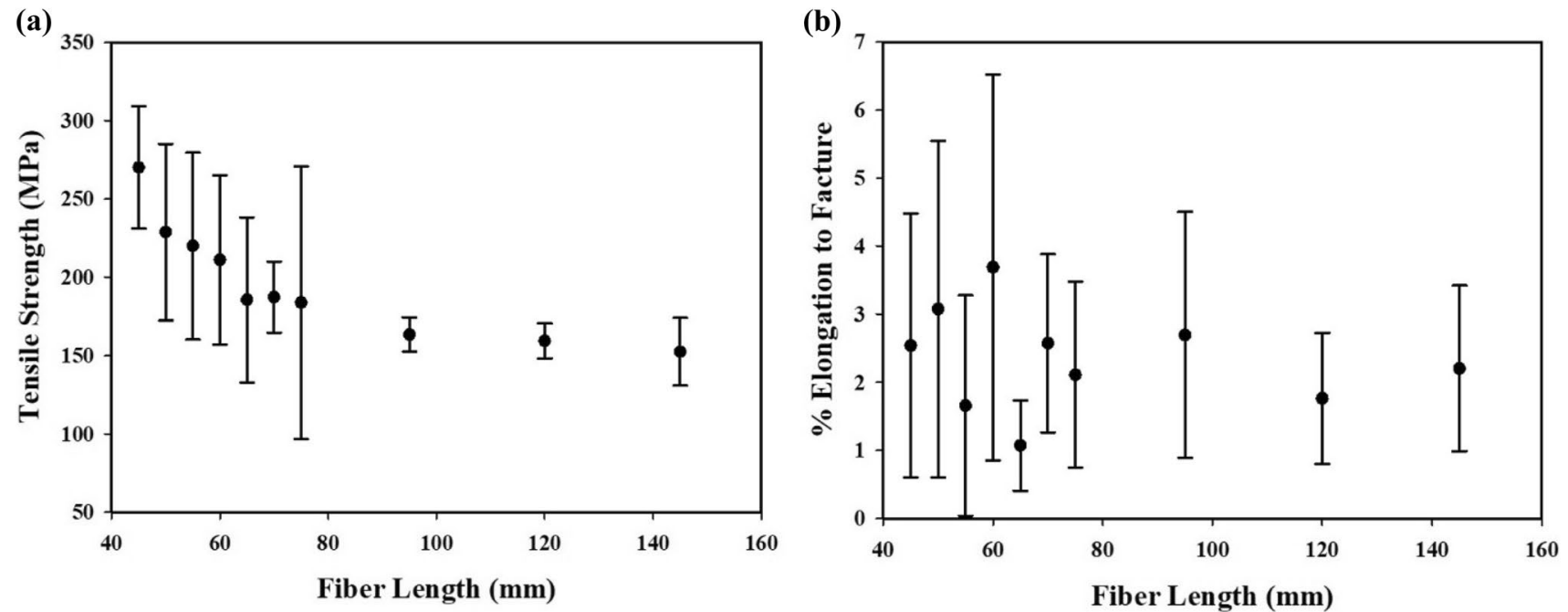

Fig. 6 Variation of a fiber fracture strength and $\mathbf{b}$ percent elongation to fracture with fiber length at a crosshead speed of $1 \mathrm{~mm} / \mathrm{min}$. Error bars are based on the standard deviation of the mean

Table 2 Properties of RPF compared with those of some natural leaf fibers

\begin{tabular}{llllll}
\hline Fiber & $\begin{array}{l}\text { Density } \\
\left(\mathrm{gcm}^{-3}\right)\end{array}$ & $\begin{array}{l}\text { Cellulose } \\
(\mathrm{wt} \%)\end{array}$ & $\begin{array}{l}\text { Tensile strength } \\
(\mathrm{MPa})\end{array}$ & $\begin{array}{l}\text { Elongation } \\
(\%)\end{array}$ & References \\
\hline Abaca & 1.50 & $56-63$ & 400 & $3-10$ & {$[11]$} \\
Sisal & 1.50 & 65.8 & $511-635$ & $2.0-2.5$ & {$[9]$} \\
Banana & 1.30 & $60-65$ & $529-914$ & $1.0-3.0$ & {$[13]$} \\
Pineapple & 1.07 & $70-82$ & 126.6 & 2.2 & {$[17]$} \\
Raffia palm fiber & $1.53 \pm 0.3$ & $53 \pm 0.9$ & $152-270$ & $2.5 \pm 1.9$ & Present study \\
\hline
\end{tabular}

Table 3 ANOVA results for tensile strength of RPFs tested using varying fiber lengths of $45,50,55,60,65,70,75,95,120$ and $145 \mathrm{~mm}$

\begin{tabular}{lrrlll}
\hline Source of variation & $d f$ & \multicolumn{1}{l}{ SS } & MS & $F$ & $p$ value \\
\hline Between groups & 9 & 30820.21 & 3424.47 & 1.45 & 0.20 \\
Within groups & 40 & 94308.65 & 2357.72 & & \\
Total & 49 & 125128.85 & & & \\
\hline
\end{tabular}

$d f$ degree of freedom, $S S$ sum of squares, $M S$ mean square, $p$ value calculated probability, $F F$ test statistic

structures of raffia fibers investigated by the authors in references $[3,19]$ in comparison to the raffia palm fiber in this study could be one of the reasons for the observed large difference. It can be observed from Fig. 6a that the fracture strength of the fiber generally decreased with fiber length. However, the results of one-way ANOVA (Table 3) suggests that the reduction in tensile strength with fiber length is not statistically significant as the $p$ value is greater than 0.05 . It was reported in some previous studies that fracture strength decreased with increasing fiber length due mainly to increase in the number of critical-sized defects as the length increased $[7,15,38,39]$. The way in which critical-sized defects are distributed in natural fibers can affect their fracture strength. If they are tangential to the direction of loading during testing, then they would have a significant effect on the strength of the fibers. In the present study, the surface defects shown in Fig. 4 run parallel to the direction of loading in the testing machine. As such, their influence on the obtained fracture strength is believed to be minimal. On the other hand, Fig. 3a shows the lumens found in the central zone of raffia palm fibers are numerous and large, thereby reducing the effective load-bearing capacity of the fiber. The effect of fiber length on elongation to fracture of the fibers is summarized in Fig. 6b. It is clear the fiber length has no appreciable effect on the percent elongation to fracture. The average percent elongation of the RPFs tested ranged from 1 to $3.8 \%$, which compares well with values of elongation obtained for Raffia textilis (2\%) [3], Raffia farinifera (4\%) [19], pineapple fiber (2.2\%) [17], sisal fiber (2-2.5\%) [9], and flax fiber (2.3-3.0\%) [5]. The results of one-way ANOVA test shown in Table 4 also showed no statically significant difference between elongation to fracture and fiber lengths investigated. 
Table 4 ANOVA results for percent elongation to fracture of 25-mm gauge length RPFs tested using varying fiber lengths of $45,50,55$, $60,65,70,75,95,120$ and $145 \mathrm{~mm}$

\begin{tabular}{lrrlll}
\hline Source of variation & $d f$ & \multicolumn{1}{c}{ SS } & MS & $F$ & $p$ value \\
\hline Between groups & 9 & 27.72 & 3.08 & 1.32 & 0.26 \\
Within groups & 40 & 93.52 & 2.34 & & \\
Total & 49 & 121.24 & & & \\
\hline
\end{tabular}

$d f$ degree of freedom, $S S$ sum of squares, $M S$ mean square, $p$ value calculated probability, $F$ F test statistic

The results of the study on the effect of crosshead speed on fiber fracture strength and percent elongation are presented in Fig. 7. As in Fig. 6, there is considerable spread in the data due to the presence of internal and external defects and variability in fiber diameter along the fiber length. Nevertheless, looking closely at the means values of strength and elongation, it appears that cross head speed had no appreciable effect on both properties. The results of one-way ANOVA of the effect of crosshead speed on fracture strength and percent elongation of the RPFs are presented in Tables 5 and 6 . With $p$ values $>0.05$ in both cases, it is concluded that there is no statistically significant difference in the fracture strength and percent elongation to fracture of the fibers as the crosshead speed was varied between 0.5 and $2.0 \mathrm{~mm} / \mathrm{min}$. The observation that the elongation to fracture of RPFs was unaffected by variation in fiber length and crosshead speed is partly consistent with the results published by in $[38,39]$ who investigated the effect of test speed on mechanical properties of sisal and curaua fibers, respectively. Both studies found that although the fracture strength of the fibers increased with strain rate, percent elongation [38] and strain at fracture [39] did not change significantly with it.

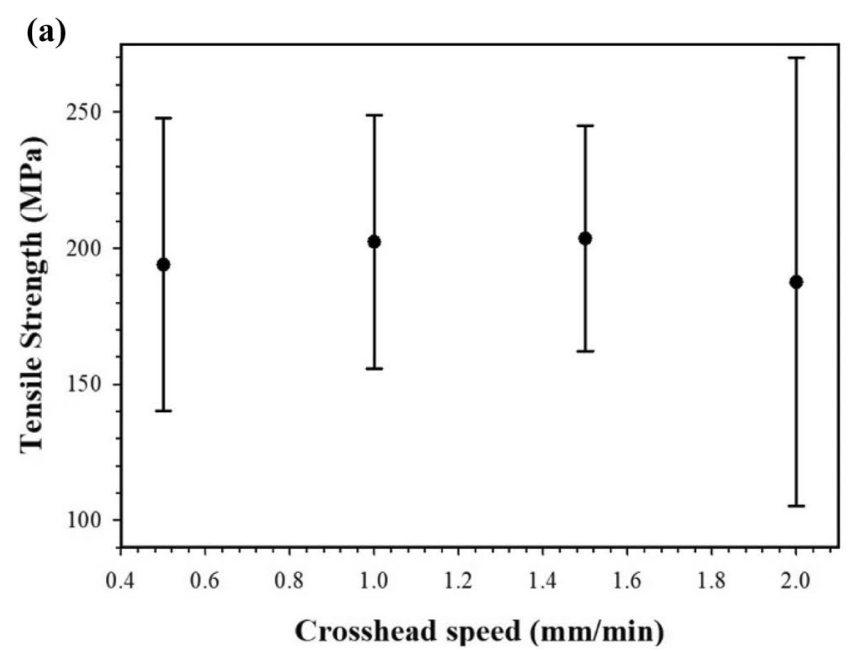

Table 5 ANOVA results for tensile strength of 50-mm gauge length RPFs tested at varying crosshead speed of $0.5,1,1.5$ and $2 \mathrm{~mm} / \mathrm{min}$

\begin{tabular}{lrrrrr}
\hline Source of variation & $d f$ & \multicolumn{1}{l}{ SS } & \multicolumn{1}{l}{ MS } & \multicolumn{1}{l}{$F$} & $p$ value \\
\hline Between groups & 3 & 1698.79 & 566.26 & 0.17 & 0.92 \\
Within groups & 36 & 122031.74 & 3389.77 & & \\
Total & 39 & 123730.53 & & & \\
\hline
\end{tabular}

$d f$ degree of freedom, $S S$ sum of squares, $M S$ mean square, $p$ value calculated probability, $F$ F test statistic

Table 6 ANOVA results for percent elongation to fracture for $25 \mathrm{~mm}$ gauge length RPFs tested at varying crosshead speed of $0.5,1,1.5$ and $2 \mathrm{~mm} / \mathrm{min}$

\begin{tabular}{lrrlll}
\hline Source of variation & \multicolumn{1}{c}{$d f$} & \multicolumn{1}{c}{ SS } & MS & $F$ & $p$ value \\
\hline Between groups & 3 & 3.00 & 1.00 & 0.59 & 0.63 \\
Within groups & 36 & 61.32 & 1.70 & & \\
Total & 39 & 64.32 & & & \\
\hline
\end{tabular}

$d f$ degree of freedom, $S S$ sum of squares, $M S$ mean square, $p$ value calculated probability, $F$ Ftest statistic

\section{Moisture adsorption and water absorption}

A typical plot showing the variation of $\%$ moisture adsorbed by raffia palm fibers as a function of time at room temperature and $50{ }^{\circ} \mathrm{C}$ is presented in Fig. 8. The data plotted for each point represent the average value for five fiber specimens. It can be seen that moisture adsorption was quite rapid in the first $20 \mathrm{~h}$ of exposure under both test conditions ( 23 and $50{ }^{\circ} \mathrm{C}$ ), after which the equilibrium saturation stage was reached. The average equilibrium moisture content obtained for RPFs at 23 and $50{ }^{\circ} \mathrm{C}$ are 6.49 and $9.39 \mathrm{wt} \%$, respectively. This suggests that the

(b)

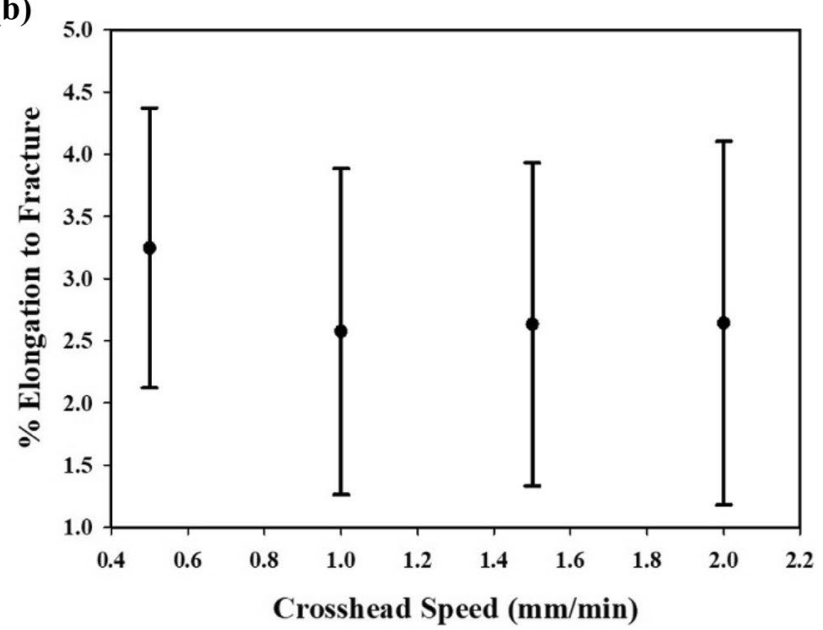

Fig. 7 Variation of $\mathbf{a}$ fracture strength and $\mathbf{b}$ percent elongation to fracture of raffia palm fibers with the crosshead speed during tensile test at a $50 \mathrm{~mm}$ fiber length. Error bars are based on the standard deviation of the mean 


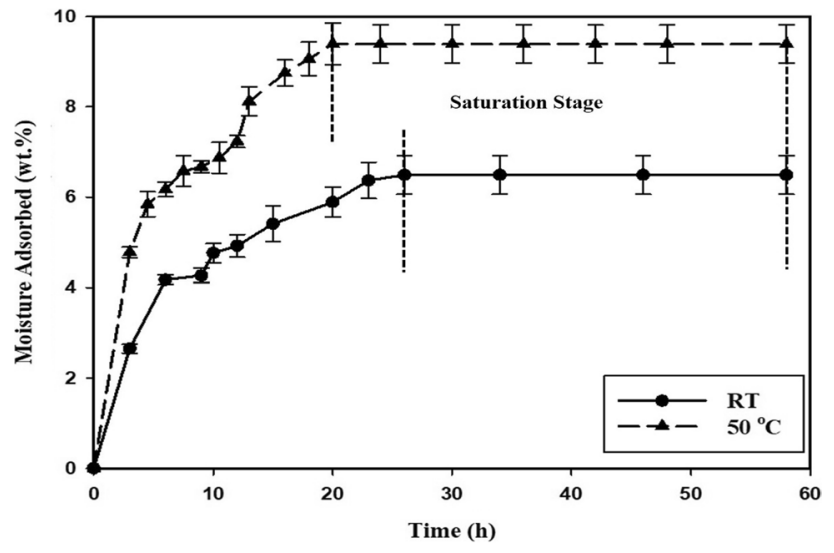

Fig. 8 Moisture adsorption behaviour of raffia palm fiber at 50\% relative humidity with different temperatures. Error bars are based on the standard deviation of the mean

temperature of the use environment has an influence on the moisture adsorption behaviour of the RPF. It can also be observed from Fig. 8 that as the exposure temperature at $50 \%$ relative humidity increased from room temperature to $50{ }^{\circ} \mathrm{C}$, the time required for the fiber to reach the saturation stage decreased from 26 to $20 \mathrm{~h}$. This value is somewhat less than values reported in the literature for other natural fibers. Fangueiro and Rana [40] measured the equilibrium moisture content of different natural fibers at $23{ }^{\circ} \mathrm{C}$ and $50 \%$ relative humidity for a week. The values obtained for flax, ramie, jute and sisal fibers were 10.6, $10.2,9.4$ and $9.5 \mathrm{wt} \%$, respectively.

Moisture adsorption behavior was investigated further by considering the shape of the curve in Fig. 8 using Eq. 4 [41].

$\frac{M_{t}}{M_{m}}=k t^{n}$.

where $M_{t}$ and $M_{m}$ denote the moisture content of the fibers at time ' $t$ ' and the average equilibrium moisture content (at saturation) of the fibers, respectively, while $k$ and $n$ are constants. The values of $k$ and $n$ obtained from a plot of $\log \left(M_{t} / M_{m}\right)$ vs $\log (t)$ (Fig. 9) represent the slope and intercept, respectively. For moisture adsorption taking place at 23 and $50{ }^{\circ} \mathrm{C}$, the calculated values of $n$ are respectively 0.96 and 0.97 . Similarly, the values of $k$ are respectively 0.33 and 0.39 at 23 and $50{ }^{\circ} \mathrm{C}$. It has been reported that a higher values of $k$ and $n$ indicates that a shorter time is required to attain moisture saturation [42]. This result further supports the earlier observation from Fig. 8 that shorter time is required for saturation for moisture adsorption at $50{ }^{\circ} \mathrm{C}$.

The results of the investigation of the variation of water uptake as a function of exposure time at room temperature are presented in Fig. 10. It is seen that the

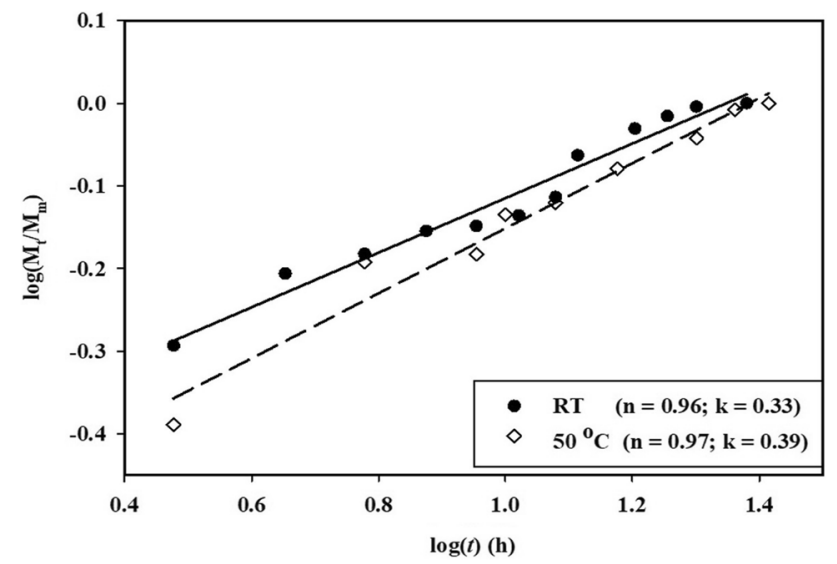

Fig. 9 Diffusion curve fitting of the moisture adsorption behaviour of raffia palm fibers at 23 and $50^{\circ} \mathrm{C}$

fibers experienced a two-stage saturation behaviour during exposure to water. One-stage saturation behaviour has been widely reported for NFs in the literature. The first saturation occurred between 130 and $202 \mathrm{~h}$ and the second occurred between 274 and $494 \mathrm{~h}$ in the current study. During the first stage of water absorption, it is believed that the lumens in the inner region of the RPFs facilitated the rapid absorption of water by capillary action [43]. The continued exposure of the samples to water permitted water absorption through the smaller internal pores in the elemental fibers (see Fig. 3c). This is probably responsible for the second saturation stage. The average equilibrium water contents at the first and second saturation stages are 56 and $62 \mathrm{wt} \%$, respectively. Kannan et al. [44] and Sampathkumar et al. [45] reported an average equilibrium water contents of 73 and $78.5 \mathrm{wt} \%$ for sisal and areca fibers, respectively.

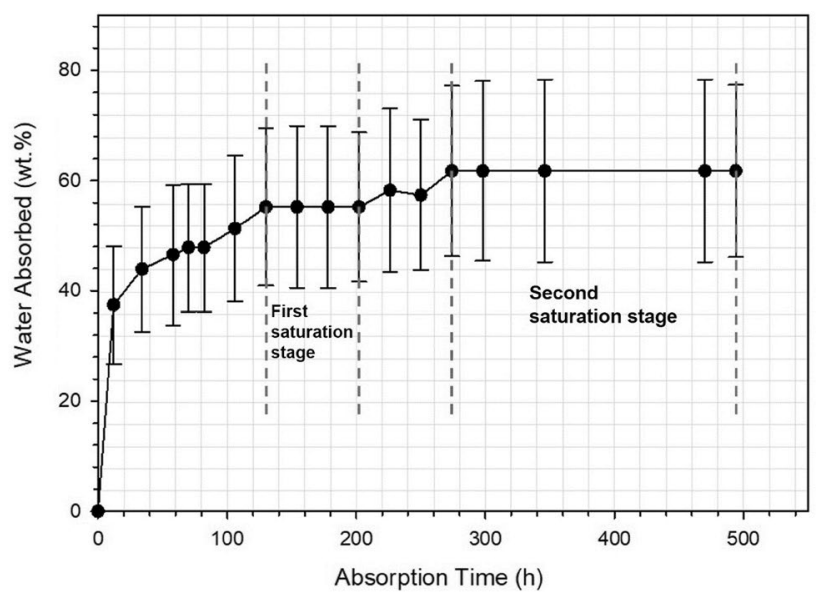

Fig. 10 Water absorption behaviour of raffia palm fibers at room temperature. Error bars are based on the standard deviation of the mean 


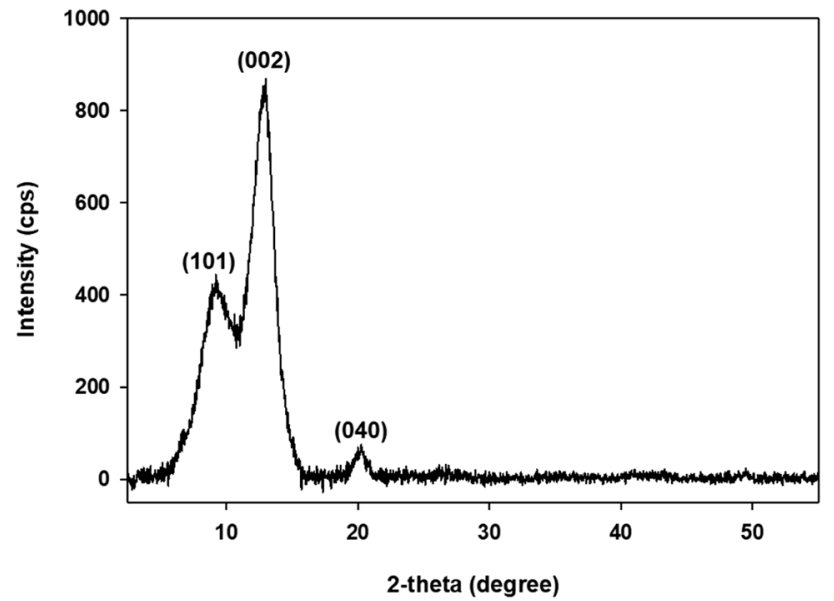

Fig. 11 Result of X-ray diffraction analysis of RPFs

\section{X-ray diffraction}

The XRD diffractogram of RPF shown in Fig. 11 exhibits the three peaks which are commonly found in natural fibers. The existence of these diffraction peaks indicates that RPF is semi-crystalline. The most prominent peaks appear at scattering angles $(2 \theta)$ of approximately $18.4^{\circ}, 26.1^{\circ}$, and $40.5^{\circ}$ which correlate to reflections from (101), (002) and (040) crystallographic planes, respectively $[30,31]$. The crystallinity index (CI) of the RPF was estimated to be $66.6 \%$. This is similar to a CI value of $66.3 \%$ obtained for curaua' fiber in [39] and a CI value of 64 that Elenga et al. [3] obtained for Raffia textilis fiber, but different from CI values of 70.9 and $45.8 \%$ obtained for sisal fiber and kapok (cotton) fiber, respectively, by Mwaikambo et al. [46].

\section{Synchrotron-based Fourier transform infrared spectromicroscopy (SB-FTIRS)}

In this study, synchrotron-based Fourier-transform infrared spectromicroscopy (SB-FTIRS) was used to map the distribution and relative concentration of the chemical constituents in RPF (cellulose, lignin and pectin). Figure 12 shows the FTIR absorption spectra obtained for each chemical component. The cellulose component of raffia palm fiber was mapped by integrating the peak around $1165 \mathrm{~cm}^{-1}$ peak $\left(1180-1140 \mathrm{~cm}^{-1}\right)$ [47, 48]. The peak at approximately $1503 \mathrm{~cm}^{-1}$ band $\left(1520-1485 \mathrm{~cm}^{-1}\right)$ was used to map the lignin component $[47,49]$, while the mapping of the pectin component was based on the $1750 \mathrm{~cm}^{-1}$ peak $\left(1780-1700 \mathrm{~cm}^{-1}\right)$, as suggested for pectin in references [48, 50]. Figure 13a shows an optical microscope image of the $170 \times 170 \mu \mathrm{m}$ region of the fiber mapped; while Fig. 13b-d provide the spatial distribution of cellulose, lignin and pectin in the fiber. Lignin is observed to be more distributed in the

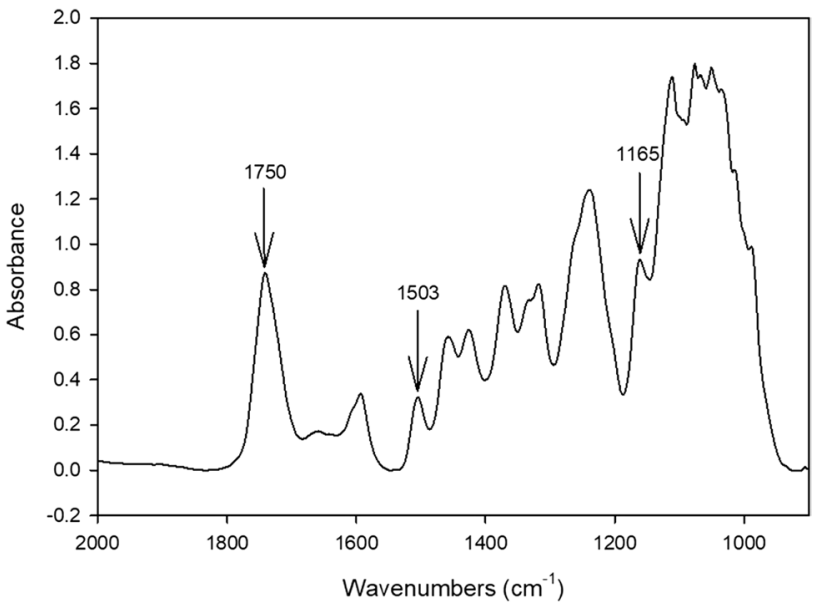

Fig. 12 Synchrotron-based Fourier-transform infrared spectra of RPF

fiber than cellulose and pectin. There is more concentration of lignin in the outer region of the fiber than cellulose and pectin which are concentrated in middle and inner regions.

\section{FTIR and Raman spectroscopy}

A typical FTIR spectrum obtained in this study for raffia fiber is presented in Fig. 14. The main features, which are typical to NFs are clearly indicated in the spectra. The large absorption band in the region of $3400-3200 \mathrm{~cm}^{-1}$ refers to $v-\mathrm{OH}$ groups and represents the hydrophilicity of the NFs [51]. The absorption peak detected at $1733 \mathrm{~cm}^{-1}$ is attributed to $v(\mathrm{C}=\mathrm{O})$ stretching of methyl ester and carboxylic acid in pectin [50]. The absorbance peak of NFs in the region of $1610 \mathrm{~cm}^{-1}$ indicates the presence of fatty acids $[46,52]$ and is attributed to $v(\mathrm{C}=\mathrm{C})$ stretching. A weak absorption peak at $1378 \mathrm{~cm}^{-1}$ was also detected, which indicates the presence of lignin [46] and is attributed to $v(\mathrm{C}=\mathrm{C})$ stretching. The absorbance peak detected around $1230 \mathrm{~cm}^{-1}$ and $1025 \mathrm{~cm}^{-1}$ is attributed to the $v(\mathrm{C}=\mathrm{O})$ and $v(\mathrm{C}-\mathrm{O}-\mathrm{C})$ stretching respectively. This absorbance peaks indicates the presence of hemicellulose in the fiber [46, 53].

Raman spectroscopy was also used to provide complementary information on the chemical structure of RPFs [54]. The absorbance peaks of interest peculiar to NFs are clearly marked in the spectra as presented in Fig. 15. The peak at $891 \mathrm{~cm}^{-1}$ correspond to $v(\mathrm{C}-\mathrm{H})$ stretching, which indicates the presence of hemicellulose for NFs [55]. The Raman peak detected around $1085 \mathrm{~cm}^{-1}$ is attributed to $v(\mathrm{C}=\mathrm{O})$ stretching of cellulose in raffia fiber [52]. The peak detected around $1587 \mathrm{~cm}^{-1}$ is attributed to $v(\mathrm{C}=\mathrm{C})$ aryl stretching of lignin [49]. Also, the peak at $1737 \mathrm{~cm}^{-1}$ which indicates the presence of waxes and fatty acids ester [49] attributed to $v(\mathrm{C}=\mathrm{O})$ vibrations was also observed. The presence of these peaks indicates that raffia fiber consists of several chemical 
Fig. 13 Synchrotron-based Fourier-transform infrared spectromicroscopy imaging of transverse section of raffia palm fiber showing a the map region of interest and chemical distribution of $\mathbf{b}$ cellulose $\left(1165 \mathrm{~cm}^{-1}\right)$, c lignin $\left(1503 \mathrm{~cm}^{-1}\right)$ and $\mathbf{d}$ pectin $\left(1750 \mathrm{~cm}^{-1}\right)$
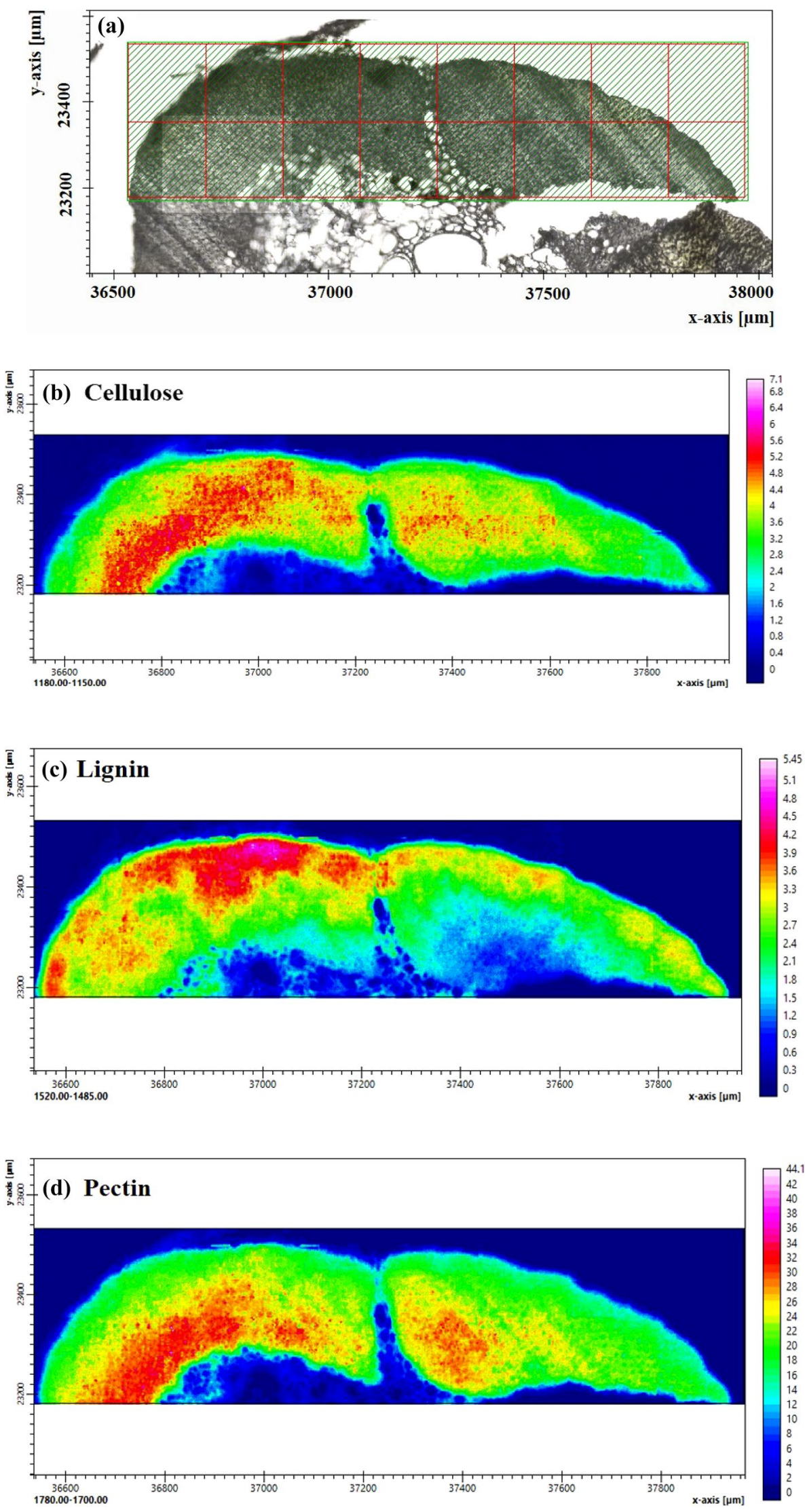


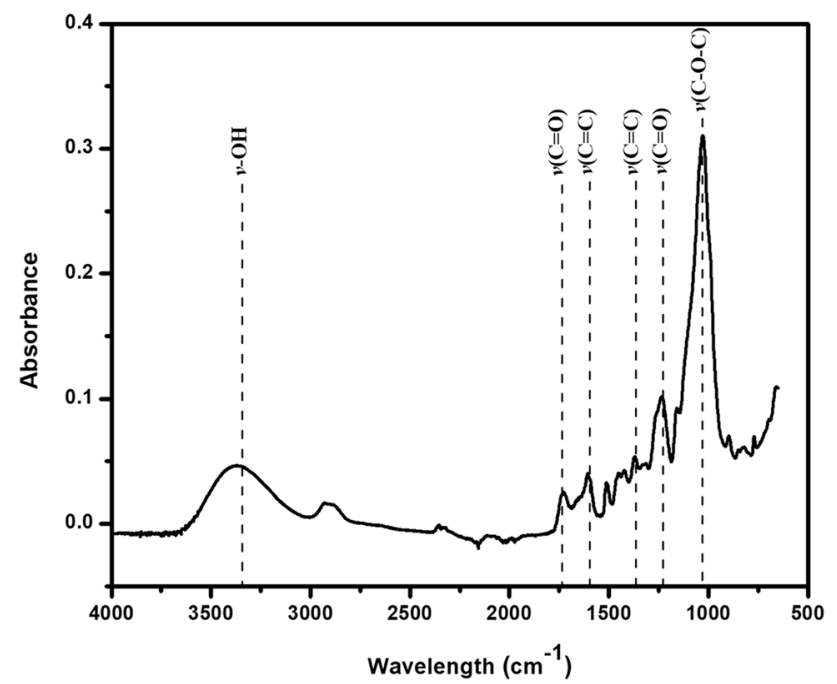

Fig. 14 Fourier transform infrared spectra of bulk raffia palm fibers

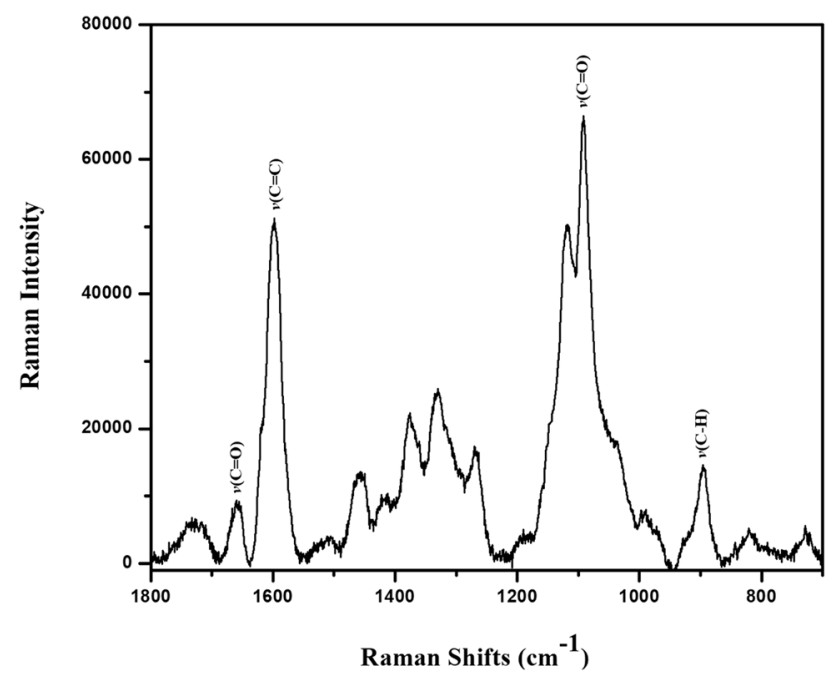

Fig. 15 Raman spectra of bulk raffia palm fibers

constituents that are similar to those found in other leaf fibers.

\section{Thermal analysis}

DSC measurements were conducted to determine the effect of water content on the overall thermal behavior of RPFs since water content has a detrimental effect on properties of polymer composites in which the fibers will be used as a reinforcement. Figure 16 shows typical DSC curves obtained for as-received and dried RPFs investigated in this study while Table 7 summarizes the key reaction peaks. The effect of drying on the first endotherm, which is due to water loss/evaporation [56-58], is well pronounced as there is a substantial change in the enthalpy and peak
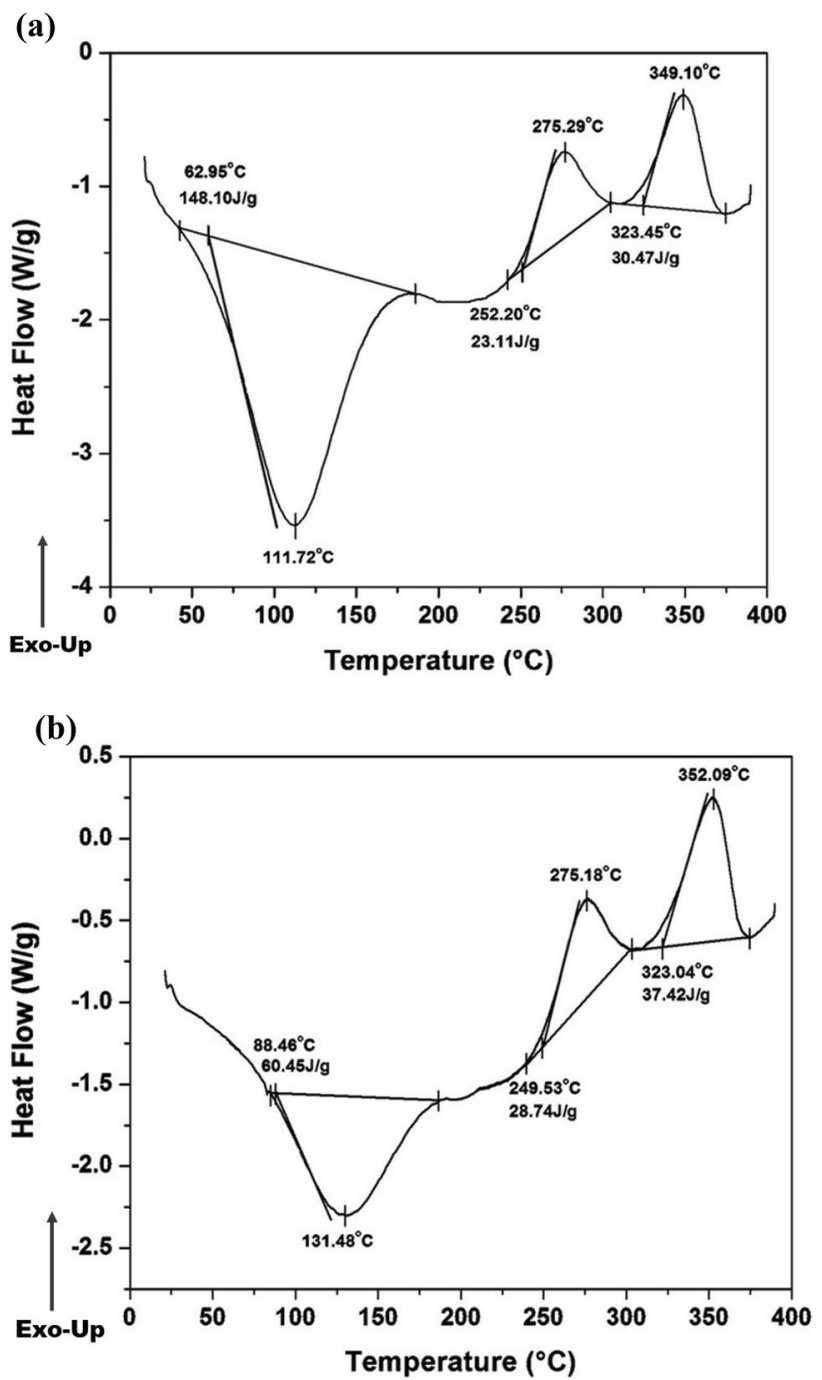

Fig. 16 DSC thermograms for $\mathbf{a}$ as-received and $\mathbf{b}$ dried RPFs

Table 7 DSC endotherm and exotherm peaks obtained for asreceived and dried RPFs

\begin{tabular}{llll}
\hline Sample & $\begin{array}{l}\text { Endo- } \\
\text { therm } \\
\left({ }^{\circ} \mathrm{C}\right)\end{array}$ & $\begin{array}{l}\text { Hemicellulose } \\
\text { degradation tem- } \\
\text { perature }\left({ }^{\circ} \mathrm{C}\right)\end{array}$ & $\begin{array}{l}\text { Cellulose degra- } \\
\text { dation tempera- } \\
\text { ture }\left({ }^{\circ} \mathrm{C}\right)\end{array}$ \\
\hline As-received fibers & 112 & 275 & 349 \\
Dried fibers & 131 & 275 & 352 \\
\hline
\end{tabular}

reaction temperature. A much higher heat was absorbed $(148 \mathrm{~J} / \mathrm{g})$ in the as-received fibers than in the dried fibers $(60 \mathrm{~J} / \mathrm{g})$. The peak reaction temperature changed from $111.72{ }^{\circ} \mathrm{C}$ in the as-received fiber to $131.48{ }^{\circ} \mathrm{C}$ in the dried fiber. Furthermore, the DSC curves of RPF show two exotherms in the temperature range $250-375^{\circ} \mathrm{C}$ which is typical of natural fibers $[57,58]$. The first exotherm with a reaction peak temperature at $275^{\circ} \mathrm{C}$ in as-received and 
dried specimens is due to decomposition of hemicellulose [56-58]. Aziz et al. [56] reported peak reaction temperatures of 255.8 and $297.5^{\circ} \mathrm{C}$ for degradation of hemicellulose in untreated hemp fiber and untreated kenaf fiber, respectively, while Hao [58] report $270{ }^{\circ} \mathrm{C}$ for both jute and kenaf fibers. Basak et al. [57] reported $291.2{ }^{\circ} \mathrm{C}$ for hemicellulose decomposition in jute fiber, while Oliveira and D'Almeida [59] obtained a decomposition temperature $270{ }^{\circ} \mathrm{C}$ for ubucu (manicaria saccifera). The second exotherm with a peak reaction temperature at $352{ }^{\circ} \mathrm{C}$ in dried $\mathrm{RPF}$ and $349^{\circ} \mathrm{C}$ in the as-received RPF is attributed to the degradation of cellulose [56-59]. In the study conducted in [56], the peak maxima obtained for cellulose decomposition in hemp and kenaf fibers were, respectively 351.8 and $347.6{ }^{\circ} \mathrm{C}$, while the authors in [59] reported $360{ }^{\circ} \mathrm{C}$ for ubucu fiber.

\section{Conclusions}

The properties of raffia palm fiber (RPF) obtained from Nigeria was investigated systematically using different materials characterization tools. Within the limit of the data obtained in this study, the following conclusions could be drawn:

1. Although its tensile strength is lower than those of flax, jute, hemp and sisal fibers, raffia palm fiber exhibited chemical, thermal, physical and elongation properties in the range found in several natural fibers that are used as reinforcements for polymers. Therefore, it has potential for use in low cost, lightweight composites.

2. The tensile strength and elongation to fracture of RPF did not change significantly with fiber length and crosshead speed within the limits of the tests conducted.

3. RPF is semi-crystalline in nature with a crystallinity index of $67 \%$. It is also hygroscopic and showed a rare two-stage water absorption behaviour.

4. Adsorbed moisture did not affect the decomposition temperatures of hemicellulose and cellulose in RPFs.

Acknowledgements Part of the research described in this paper was performed at the Canadian Light Source, which is supported by the Canada Foundation for Innovation, Natural Sciences and Engineering Research Council of Canada, the University of Saskatchewan, the Government of Saskatchewan, Western Economic Diversification Canada, the National Research Council Canada, and the Canadian Institutes of Health Research. We acknowledge Mr. Jarvis Stobbs and Dr. Na Liu from the Canadian Light Source for their support in sample preparation for the FTIRS and training for data collection, respectively. We also acknowledge Dr. L. Tabil for the use of his tensile testing machine and gas pycnometer.

\section{Compliance with ethical standards}

Conflict of interest The authors declare that they have no conflict of interest.

\section{References}

1. Santhosh J, Balanarasimman N, Chandrasekar R, Raja S (2014) Study of properties of banana fiber reinforced composites. Int J Res Eng Technol 3:144-150

2. Thiruchitrambalam M, Athijayamani A, Sathiyamurthy S, Thaheer ASA (2010) A review on the natural fiber-reinforced polymer composites for the development of roselle fiber-reinforced polyester composite. J Nat Fibers 7:307-323

3. Elenga RG, Dirras GF, Goma MJ, Djemia P, Biget MP (2009) On the microstructure and physical properties of untreated raffia textilis fiber. Compos Part A Appl Sci Manuf 40:418-422

4. Mohammed L, Ansari MNM, Pua G, Jawaid M, Islam MS (2015) A review on natural fiber reinforced polymer composite and its applications. Int J Polym Sci. https://doi. org/10.1155/2015/243947

5. Chinga-carrasco G, Aslan M, Sørensen BF, Madsen B (2011) Strength variability of single flax fibres. J Mater Sci 46:6344-6354

6. Li X, Panigrahi S, Tabil LG (2009) A study on flax fiber-reinforced polyethylene biocomposites. Appl Eng Agric 25:525-531

7. Silva F, de A, Chawla, N, Filho RD de T (2008) Tensile behavior of high performance natural (sisal) fibers. Compos Sci Technol 68:3438-3443

8. Li Y, Mai Y-W, Ye L (2000) Sisal fibre and its composites: a review of recent developments. Compos Sci Technol 60:2037-2055

9. Bledzki AK, Gassan J (1999) Composites reinforced with cellulose based fibers. Prog Polym Sci 24:221-274

10. Cai M, Takagi H, Nakagaito AN, Katoh M, Ueki T, Waterhouse GIN, Li Y (2015) Influence of alkali treatment on internal microstructure and tensile properties of abaca fibers. Ind Crops Prod 65:27-35

11. Faruk O, Bledzki AK, Fink HP, Sain M (2012) Biocomposites reinforced with natural fibers: 2000-2010. Prog Polym Sci 37:1552-1596

12. Punyamurthy R, Sampathkumar D, Bennehalli B, Patel R, Venkateshappa SC (2014) Abaca fiber reinforced epoxy composites: evaluation of impact strength. Int J Sci Basic Appl Res 18:305-317

13. Pujari S, Ramakrishna A, Kumar MS (2014) Comparison of jute and banana fiber composites: a review. Int J Curr Eng Technol Special Issue 2:121-126. https://doi.org/10.14741/ijcet/ spl.2.2014.22

14. Ronald Aseer J, Sankaranarayanasamy K, Jayabalan P, Natarajan R, Dasan KP (2013) Morphological, physical, and thermal properties of chemically treated banana fiber. J Nat Fibers 10:365-380

15. Mathura N, Cree D (2016) Characterization and mechanical property of Trinidad coir fibers. J Appl Polym Sci 133:43692. https:// doi.org/10.1002/app.43692

16. Mir SS, Hasan M, Hasan SMN, Hossain MJ, Nafsin N (2015) Effect of chemical treatment on the properties of coir fiber reinforced polypropylene and polyethylene composites. Polym Compos 38:1259-1265

17. Arib RMN, Sapuana SM, Ahmada MMHM, Paridah MT, Khairul Zamanc HMD (2006) Mechanical properties of pineapple leaf fibre reinforced polypropylene composites. Mater Des 27:391-396 
18. Zhang Y, Wen B, Cao L, Li X, Zhang J (2015) Preparation and properties of unmodified ramie fiber reinforced polypropylene composites. J Wuhan Univ Technol Sci Ed 30:198-202

19. Sandy M, Bacon L (2001) Tensile testing of raffia. J Mater Sci Lett 20:529-530

20. Kocak D, Merdan N, Evren OB (2015) Research into the specifications of woven composites obtained from raffia fibers pretreated using the ecological method. Text Res J 85:302-315

21. Elenga RG, Dirras GF, Maniongui JG, Mabiala B (2011) Thin-layer drying of Raffia textilis fiber. BioResources 6:4135-4144

22. Odera RS, Onukwuli OD, Atuanya CU (2015) Characterization of the Thermo-microstructural analysis of raffia palm fibers proposed for roofing sheet production. J Miner Mater Charact Eng 3:335-343

23. Soleimani M, Tabil L, Panigrahi S, Opoku A (2008) The effect of fiber pretreatment and compatibilizer on mechanical and physical properties of flax fiber-polypropylene composites. J Polym Environ $16: 74-82$

24. Jin W, Singh K, Zondlo J (2013) Pyrolysis kinetics of physical components of wood and wood-polymers using isoconversion method. Agriculture 3:12-32

25. Ankom Technology (2000) Acid detergent fiber in feeds-filter bag technique. Method 5:6-7

26. Ankom Technology (2011) Neutral detergent fiber in feeds-filter bag technique. Method 6:10-11

27. Ankom Technology (2013) Determining acid detergent lignin in beakers. Method 8:11-12

28. ASTM D3822/D3822M-14 (2014) Standard test method for tensile properties of single textile fibers. ASTM International

29. Segal L, Creely JJ, Martin AE, Conrad CM (1959) An empirical method for estimating the degree of crystallinity of native cellulose using the X-ray diffractometer. Text Res J 29:786-794

30. Sathitsuksanoh N, Zhu Z, Wi S, Percival Zhang YH (2011) Cellulose solvent-based biomass pretreatment breaks highly ordered hydrogen bonds in cellulose fibers of switchgrass. Biotechnol Bioeng 108:521-529

31. Du R, Su R, Qi W, He Z (2018) Enhanced enzymatic hydrolysis of corncob by ultrasound-assisted soaking in aqueous ammonia pretreatment. Biotech 8:1-7

32. Turunen MJ, Saarakkala S, Rieppo L, Helminen HJ, Jurvelin JS, Isaksson H (2011) Comparison between infrared and raman spectroscopic analysis of maturing rabbit cortical bone. Appl Spectrosc 65:595-603

33. Schrader B (2007) Infrared and raman spectroscopy: methods and applications. VCH Publ Inc, New York. https://doi. org/10.1002/9783527615438

34. Tran LQN, Nguyen Minh T, Fuentes CA, Truong Chi T, Van Vuure $\mathrm{AW}$, Verpoest I (2015) Investigation of microstructure and tensile properties of porous natural coir fibre for use in composite materials. Ind Crops Prod 65:437-445

35. Alves Fidelis ME, Pereira TVC, Gomes ODFM, De Andrade Silva F, Toledo Filho RD (2013) The effect of fiber morphology on the tensile strength of natural fibers. J Mater Res Technol 2:149-157

36. Wang F, Shao J, Keer LM, Li L, Zhang J (2015) The effect of elementary fibre variability on bamboo fibre strength. Mater Des 75:136-142

37. Eichhorn SJ, Hughes M, Snell R, Mott L (2000) Stress induced shifts in the Raman spectra of natural cellulose fibers. J Mater Sci Lett 19:721-723

38. Mukherjee PS, Satyanarayana KG (1984) Structure and properties of some vegetable fibres. J Mater Sci 19:3925-3934

39. Tomczak F, Satyanarayana KG, Sydenstricker THD (2007) Studies on lignocellulosic fibers of Brazil: Part III-morphology and properties of Brazilian curaua fibers. Compos Part A Appl Sci Manuf 38:2227-2236
40. Fangueiro R, Rana S (2015) Natural fibres: advances in science and technology towards industrial applications. Springer Nat 12:37-43

41. Espert A, Vilaplana F, Karlsson S (2004) Comparison of water absorption in natural cellulosic fibres from wood and one-year crops in polypropylene composites and its influence on their mechanical properties. Compos Part A Appl Sci Manuf 35:1267-1276

42. Mat-Shayuti MS, Abdullah MZ, Megat-Yusoff PS (2013) Water absorption properties and morphology of polypropylene/polycarbonate/polypropylene-graft-maleic anhydride blends. Asian J Sci Res 6:167-176

43. Jacob M, Varughese KT, Thomas S (2005) Water sorption studies of hybrid biofiber-reinforced natural rubber biocomposites. Biomacromol 6:2969-2979

44. Kannan R, Anand AV, Hariprasad V, Sing RA, Jayalakshmi S, Arumugam V (2017) Effect of cashew nut shell oil (Cardanol) on water absorption and mechanical characteristics of sisal fibers. In : Proceedings of the International Conference on Recent Innovations in Production Engineering, Chennai, India. ISBN:978-93-86256-65-2

45. Sampathkumar D, Punyamurth R, Venkateshappa SC (2012) Effect of chemical treatment on water absorption of areca fiber. J Appl Sci Res 8:5298-5305

46. Mwaikambo LY, Ansell MP (2002) Chemical modification of hemp, sisal, jute, and kapok fibers by alkalization. J Appl Polym Sci 84:2222-2234

47. Yu P (2005) Molecular chemistry imaging to reveal structural features of various plant feed tissues. J Struct Biol 150:81-89

48. Yu P, McKinnon JJ, Christensen CR, Christensen DA (2004) Imaging molecular chemistry of pioneer corn. J Agric Food Chem 52:7345-7352

49. Edwards HG, Farwell DW, Webster D (1997) FT Raman microscopy of untreated natural plant fibres. Spectrochim acta Part A 53:2383-2392

50. Ouajai S, Shanks RA (2005) Composition, structure and thermal degradation of hemp cellulose after chemical treatments. Polym Degrad Stab 89:327-335

51. Tibolla H, Pelissari FM, Menegalli FC (2014) Cellulose nanofibers produced from banana peel by chemical and enzymatic treatment. LWT Food Sci Technol 59:1311-1318

52. Gierlinger N, Schwanninger M, Reinecke A, Burgert I (2006) Molecular changes during tensile deformation of single wood fibers followed by Raman microscopy. Biomacromol 7:2077-2081

53. Udoetok IA, Wilson LD, Headley JV (2016) Quaternized cellulose hydrogels as sorbent materials and pickering emulsion stabilizing agents. Materials (Basel) 9:1-16

54. Jähn A, Schröder MW, Füting M, Schenzel K, Diepenbrock W (2002) Characterization of alkali treated flax fibres by means of FT Raman spectroscopy and environmental scanning electron microscopy. Spectrochim Acta Part A 58:2271-2279

55. Himmelsbach DS, Akin DE (1998) Near-infrared Fourier-transform Raman spectroscopy of flax (Linum usitatissimum L.) stems. J Agric Food Chem 46:991-998

56. Aziz SH, Ansell MP (2004) The effect of alkalization and fibre alignment on the mechanical and thermal properties of kenaf and hemp bast fibre composites: Part 1 - polyester resin matrix. Composit Sci Technol 64:1219-1230

57. Basak RK, Saha SG, Sarkar AK, Saha M, Das NN, Mukherjee AK (1993) Thermal properties of jute constituents and flame retardant jute fabrics. Text Res J 63:658-666

58. Hao A (2013) Mechanical and thermal properties of kenaf polypropylene nonwoven composites. Ph.D. Thesis; Univ Texas, Texas, USA, pp 19-30

59. Oliveira AKF, d'Almeida JRM (2014) Characterization of ubuçu (Manicaria saccifera) natural fiber mat. Polym Renew Resour $5: 13-28$ 